\title{
The peri-urban leopards of Kathmandu: assessing determinants of presence and predation on domestic animals
}

\author{
Ashish Bista, Pranav ChanChani \\ NARESh Subedi and Siddhartha B. BajRACHARYA
}

\begin{abstract}
The conservation of large carnivores in humandominated landscapes needs to be reconciled with the safety of humans and domestic animals. This is especially true for the leopard Panthera pardus, which occurs extensively in agricultural landscapes and remnant forest tracts embedded within peri-urban areas such as Kathmandu district in Nepal. We carried out interviews in 321 households in this district to determine the extent of leopard habitat use and predation on domestic animals (dogs and goats) during October 2015-April 2016. We used multi-state occupancy models, and estimated probabilities of leopard habitat use $\left(\Psi_{1}\right)$ and predation on domestic animals $\left(\Psi_{2}\right)$ as a function of covariates, while accounting for imperfect detection. Our findings indicate that the rapidly urbanizing outskirts of Kathmandu city are used extensively by leopards. The estimated probability of fine-scale habitat use in $2 \mathrm{~km}^{2}$ sample units was $0.96 \pm$ SE 0.05 and the probability of predation on domestic animals was $0.76 \pm$ SE 0.15 . Leopard attacks occurred in areas with high vegetation cover and abundant goats. Addressing the problem of leopard attacks on domestic animals will require developing a comprehensive mitigation plan that includes educational activities to raise awareness, measures to address grievances of affected local communities, interventions to prevent attacks on livestock, compensation programmes, and rapid response teams to ensure human and animal welfare in conflict-prone areas. Land-use planning in these peri-urban landscapes needs to facilitate the safe sharing of space between people and leopards.
\end{abstract}

Keywords Carnivore conservation, habitat use, humanleopard conflict, Kathmandu, leopard, occupancy models, Panthera pardus, urban wildlife

\footnotetext{
Ashish Bista* (Corresponding author) and Pranav Chanchani World Wide Fund for Nature, 172-B Lodhi Estate, New Delhi, 110003, India E-mail ashishbista1@gmail.com

Naresh Subedi and Siddhartha B. BajRacharya National Trust for Nature Conservation, Khumaltar, Lalitpur, Nepal

${ }^{\star}$ Previously at: National Trust for Nature Conservation, Khumaltar, Lalitpur, Nepal

Received 6 January 2020. Revision requested 13 March 2020.

Accepted 7 May 2020. First published online 4 May 2021.
}

\section{Introduction}

T. umans and large carnivores co-occur extensively where 1 urban areas expand into or surround wildlife habitats (Zérah, 2007). Although large mammals do not always persist in areas with high anthropogenic pressure (Woodroffe, 2000; Ripple et al., 2017), they sometimes adapt to human-modified habitats including the edges of populous towns and farmlands, often sheltering, feeding and breeding in such areas (Gehrt, 2007; Beckmann \& Lackey, 2008; Bateman \& Fleming, 2012; Athreya et al., 2014; Odden et al., 2014). The conservation of large carnivores presents a conundrum for wildlife managers and local administrators who are tasked with protecting wildlife and ensuring the safety of local communities (Allendorf, 2010). This task is especially challenging when carnivores occur on privately owned land (Enserink \& Vogel, 2006), where there is an elevated risk of negative interactions with people (Nyhus \& Tilson, 2004).

The leopard Panthera pardus commonly occurs in close proximity to human settlements (Odden \& Wegge, 2005; Odden et al., 2014). There are many drivers for leopard occurrence in human-dominated landscapes, including habitat fragmentation, wild prey depletion, attraction to domestic animals as easy prey and competitive displacement as a result of inter- or intra-species interactions (Seidensticker, 1976; Odden et al., 2010; Ripple et al., 2014). Several studies show that home ranges of leopards sometimes overlap partially or completely with human-use areas (e.g. Odden et al., 2010, 2014), which is facilitated by the species' dietary plasticity. Leopards readily adapt to prey on domestic animals, particularly dogs, which may comprise as much as $70 \%$ of their diet (Karanth \& Sunquist, 2000; Edgaonkar \& Chellam, 2002; Dickman \& Marker, 2005; Athreya et al., 2014; Kumbhojkar et al., 2020).

Predation of domestic animals by leopards is common across many Asian and African range countries (Kissui, 2008; Dar et al., 2009; Khorozyan et al., 2017; Kshettry et al., 2017). Such predation, especially on livestock, causes economic losses (Dar et al., 2009), can affect the livelihoods and social well-being of people (Barua et al., 2013; Kshettry et al., 2018), engenders negative attitudes of people towards carnivores (Megaze et al., 2017) and may catalyse retaliatory killing by poisoning or other means (Ogada et al., 2003).

In Nepal, human-leopard conflict is a serious issue (Acharya et al., 2016). Adverse interactions with humans 
are more likely when leopards occur in densely populated peri-urban areas (Soulsbury \& White, 2016), such as Kathmandu district. Inclusive of Kathmandu, the country's capital city, this district has a population of $>1.7$ million people, with a population density of 4,416 people $/ \mathrm{km}^{2}$ (25 times higher than the national average; CBS, 2014). The city and its suburbs are surrounded by montane forests, most notably the Shivapuri-Nagarjun National Park and National Forest, which supports a leopard population (Pokharel, 2015). Leopards sometimes enter human settlements, including the fringes of Kathmandu city, and are subsequently captured and translocated to zoos or released back into the wild. Although leopards are routinely captured in the Kathmandu valley, the extent of their occurrence and predation on domestic animals has hitherto not been thoroughly investigated (Pokharel, 2015).
Here, we assessed the extent and determinants of leopard habitat use and predation on domestic animals in periurban areas within Kathmandu district, with the aim of assisting the Government of Nepal in devising strategies to mitigate future human-leopard conflict.

\section{Study area}

We conducted this study in 10 of 11 municipalities in Kathmandu district, Nepal (395 km²; Fig. 1). Kathmandu district is one amongst three districts located within the Kathmandu valley, and is home to $>72$,0oo households (CBS, 2014). The predominant land-use types are forest $(42 \%)$, farmland (42\%) and built-up areas (14\%; Wang et al., 2020). Along with a rapid increase in the human population, urban areas expanded by $412 \%$ in the

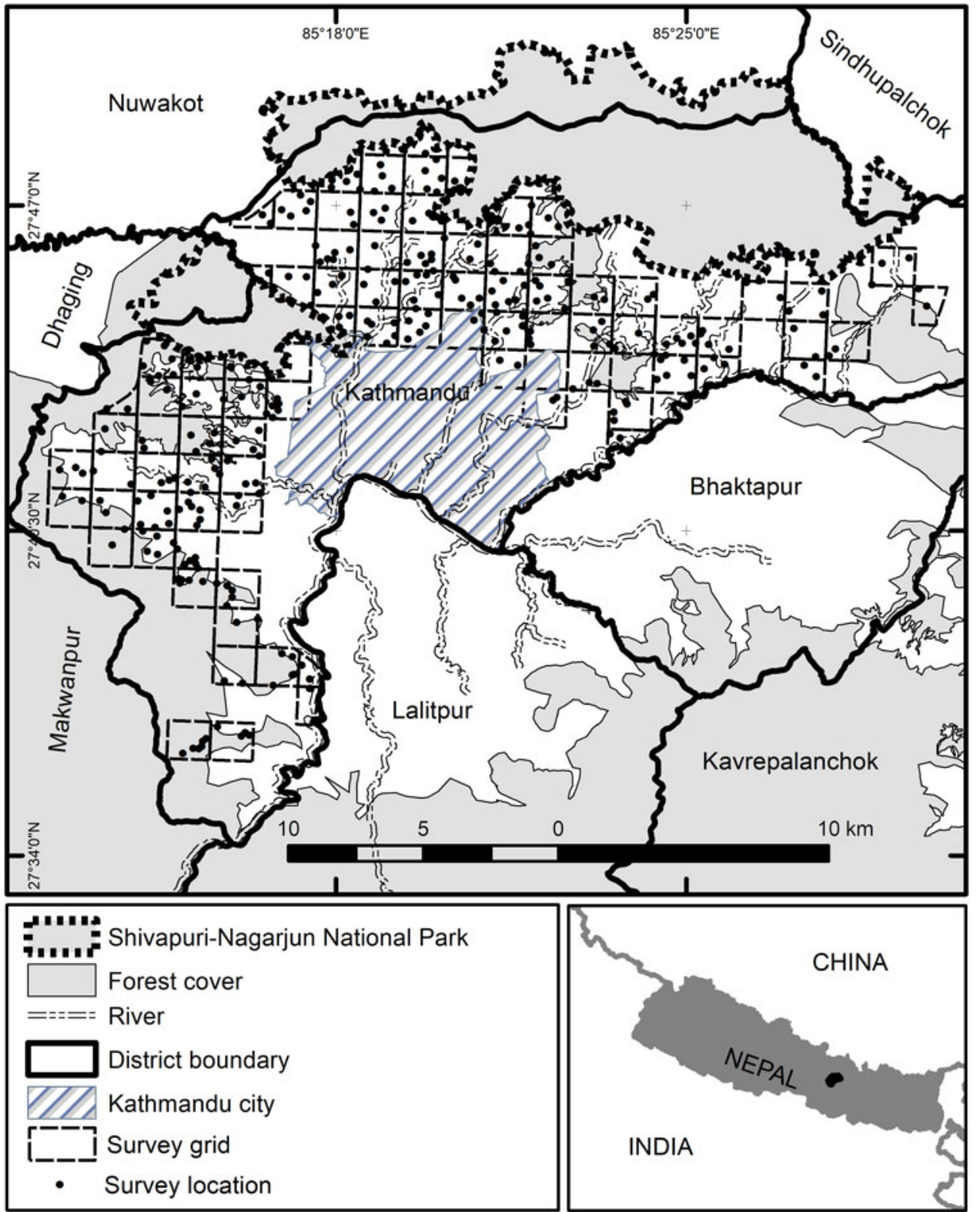

FIg. 1 Study area showing Kathmandu district, Kathmandu city and survey locations within $902-\mathrm{km}^{2}$ grid cells. The inset map shows the location of the study area within Nepal. 
Kathmandu valley since 1989 , with conversion of $31 \%$ of farmlands (Ishtiaque et al., 2017). Most communities in Kathmandu district outside the city are agrarian, with rice, wheat, maize, potato and mustard being the main crops.

The forested hills around Kathmandu district (Fig. 1) are managed by the administration of Shivapuri-Nagarjun National Park $\left(159 \mathrm{~km}^{2}\right)$ and the Kathmandu District Forest Office as National Forest, Community Forest and others $\left(132 \mathrm{~km}^{2}\right)$. These forests support diverse mammalian and avian communities. The vegetation is sub-tropical/temperate forest dominated by Pinus spp., Quercus spp. and Castanopsis spp. (Shrestha, 2001). These forests contribute to the provision of drinking water and clean air for the 1.7 million inhabitants of Kathmandu district, and are valuable for religious and cultural reasons (SSNP, 2017).

\section{Methods}

\section{Interview surveys}

We divided the study area into $2-\mathrm{km}^{2}$ grid cells (Fig. 1 ) and carried out interview surveys in 90 of these cells (sites), to collect information on leopard occurrence and predation on domestic animals. A two-member survey team was trained to undertake the interview surveys. The team interviewed 2-6 households in each grid cell during October 2015-April 2016. Following Athreya et al. (2015) and Zeller et al. (2011), each household was treated as a discrete sampling occasion. Adult residents in each household were asked whether they had detected leopard presence or knew of leopard predation on domestic animals in the immediate neighbourhood (within c. $500 \mathrm{~m}$ of their home) over the past year. We only considered the immediate neighbourhood so that we could reliably assign reported predation events to individual grid cells. To avoid ambiguity regarding the identity of the predator, respondents were asked to provide clear descriptions of the species and its signs, or distinguish these from images of various carnivores and their pugmarks. We only recorded leopard presence and/or predation when respondents provided an accurate description of the species. In the case of reported depredation of domestic animals, the interviewers recorded information on the species of domestic animal, count of events and their locations. All interviews were carried out in Nepali.

\section{Covariates and hypotheses}

We collated data for a total of five covariates (Table 1). We determined the relative abundance of dogs and goats (covariates $d o g$ and goat, respectively) during field surveys and derived the other three covariates from remotely sensed data: normalized difference vegetation index (NDVI; covariate $n d v i$ ), Euclidean distance from the centre of the grid cell

TABLE 1 List of covariates used to model probabilities of leopard Panthera pardus habitat use $\left(\Psi_{1}\right)$ and predation on domestic animals $\left(\Psi_{2}\right)$ in Kathmandu district, Nepal.

Covariates associated with occurrence of leopards and predation on domestic animals (range) Distance to forest $(0-3.1 \mathrm{~km})$

Normalized difference vegetation index (including forest \& cultivated land) in humandominated landscape (0.01-0.95)

Dog abundance (0-2.5)

Goat abundance (0-18.6)

River length (0-5.0 km)
Grids with greater vegetation cover will be associated with higher leopard presence

Leopard use is expected to be higher in sites with higher relative abundance of dogs

Habitat use is expected to be higher in sites with higher relative abundance of goats

Leopards will extensively use rivers \& drainage features, which provide cover, $\&$ access to food sources around human settlements

Expected influence on detecting use when true occupancy state is $1\left(p_{1}\right) \& 2\left(p_{2}\right)$ occurrence of predatio Sites close to forest are Higher predation of domestic animals is expected closer to forests expected to be associated with higher detection of leopard presence \& predation $\left(p_{1}\right)\left(p_{2}\right)$

Sites with higher vegetation cover will have higher predation Detection probability of leopards likely to be higher in grid cells with more vegetation
Sites with more dogs will have higher rates of predation

Sites with more goats will have higher rates of predation

Higher rates of predation are expected in grid cells with greater cumulative length of rivers because of higher leopard presence 
to the nearest forest patch (covariate distoforest), and the cumulative length of rivers in each grid cell (covariate river). We used ArcGIS 10.2 (Esri, Redlands, USA) for spatial analyses.

We hypothesized that dogs were likely to attract leopards to settlements (Table 1), as they are important in the leopard's diet (Edgaonkar \& Chellam, 2002; Athreya et al., 2014). However, in grid cells with high dog numbers (beyond a certain threshold) we speculated that leopard predation on dogs may decline as packs of dogs are known to chase off leopards and alert people to the felids' presence (Young et al., 2011; Potgieter et al., 2015). We counted all dogs within $150 \mathrm{~m}$ of surveyed homes and calculated an encounter rate following Krishna et al. (2008):

$$
\text { Index }=\frac{\text { No. of dogs }}{\text { No. of households surveyed in grid cell }}
$$

Leopards prefer medium-sized prey (Karanth \& Sunquist, 1995; Hayward et al., 2006). During interviews, we therefore recorded the number of goats kept by respondents. We then calculated a goat abundance index as described above for dog abundance. We expected high probabilities of leopard presence and predation on domestic animals in grid cells with higher goat abundance (Hayward et al., 2006; Sangay \& Vernes, 2008; Table 1). In addition, we predicted that probabilities of leopard occurrence and predation on domestic animals would both decline as a function of distance to forest edge, because urban and built-up areas provide less suitable cover for leopards (Table 1). The NDVI is an indicator of green vegetation (Krishna et al., 2008), which we used as a proxy for cover. We predicted that areas with dense vegetation cover would be more likely to harbour leopards (Kshettry et al., 2017). We also predicted that cells with more vegetation cover would have higher rates of predation on goats and dogs, because leopards can remain concealed while stalking or feeding on prey (Table 1). Carnivores commonly use water courses as movement routes (Smith, 1993), and we thus expected the cumulative length of rivers in a grid cell to positively influence habitat use by leopards and predation. We expected higher detection probabilities near forests because people residing there were more likely to encounter and report leopards. We also expected that detectability would be higher in cells with high vegetation cover as leopard presence would be reported more frequently in such grid cells, because we expected greater leopard occurrence in cells with higher NDVI (Table 1).

\section{Habitat use states and model parameters}

We used multi-state occupancy models to concurrently test our hypotheses about the predictors of leopard habitat use and predation on domestic animals (Nichols et al., 2007; Athreya et al., 2015). We interpret the parameter $\Psi_{1}$ as estimated proportion of habitat use and parameter $\Psi_{2}$ as probability of depredation in sites with habitat use, rather than occupancy, because the size of the sample unit is small relative to the home range of leopards (MacKenzie et al., 2006; Zeller et al., 2011). We defined three discrete habitat-use and predation states in our detection matrix: unoccupied (state o), occupied with no predation on domestic animals (state 1) and occupied with predation on domestic animals (state 2). For each interview survey, we recorded 'o' when no leopard presence was reported, and ' 2 ' when one or more events of predation on domestic animals were reported. We recorded ' 1 ' when leopard presence was reported without mention of depredation. State 1 carries a level of uncertainty: it could either be a correct assignment (leopards present but not preying on domestic animals), or an incorrect assignment (actual situation is state 2, but respondent is unaware of depredation event).

Our multi-state occupancy model included five parameters (following Nichols et al., 2007). $\Psi_{1}$ is the probability of site use by leopards, regardless of whether or not predation on domestic animals occurs. $\Psi_{2}$ is the probability that depredation occurs, in the event that the site is used by leopards. The parameter $p_{1}$ is the probability of leopard presence being reported in cases where the true state is 1 , and $p_{2}$ is the probability of leopard presence being reported where the true state is 2 . The parameters $p_{1}$ and $p_{2}$ address state uncertainty because depredation events may or may not be reported in sites where leopards are present. We also estimated $\delta$, which is the probability of finding evidence for leopard predation on domestic animals in cells where the true state is 2 (leopards are present and predating on livestock).

\section{Data analysis}

Prior to model-building, we tested for collinearity among the covariates, and found they were not correlated $(r<0.5)$. We adopted a two-step process to model the effects of covariates to estimate model parameters (Athreya et al., 2015). Firstly, we sought to explain variation in the detection process by modelling distance to forest and NDVI, by building 15 alternate models (covariates modelled singly, additively and a null model; Table 2). In this step, we used a global model for the parameters habitat use $\left(\Psi_{1 \text { ndvi+dog+goat+river+distoforest }}\right)$ and predation on domestic animals $\left(\Psi_{2}\right.$ ndvi+dog+goat+river+distoforest $)$. We compared models using the Akaike information criterion adjusted for small sample size (AICc), to determine the optimal detection parameterization, which was retained in the next modelling step (Table 2).

In the second step, we tested our hypotheses about the spatial variation in leopard habitat use and predation on domestic animals. For this, we retained the covariate combination for detection parameters from the best supported model from the previous step, and tested our hypotheses 
TABLE 2 Model results for detection parameters, $p_{1}$ (leopard detection probability) and $p_{2}$ (detection probability of predation on domestic animals). Two covariates $n d v i$ and distoforest were modelled with global model $\Psi_{1}($ dog + goat $+n d v i+$ river + distoforest $), \Psi_{2}($ dog + goat $+n d v i$ +river+distoforest).

\begin{tabular}{|c|c|c|c|c|c|c|}
\hline Model $^{1}$ & $\mathrm{AICc}^{2}$ & $\Delta \mathrm{AICc}^{3}$ & Akaike weight & Model likelihood & No. of parameters & Deviance \\
\hline$\overline{p_{1}(.), p_{2}(\text { distoforest }), \delta(.)}$ & 516.39 & 0.00 & 0.25 & 1.00 & 16 & 476.94 \\
\hline$p_{1}(),. p_{2}(n d v i+$ distoforest $), \delta()$. & 517.37 & 0.98 & 0.15 & 0.61 & 17 & 474.87 \\
\hline$p_{1}($ distoforest $), p_{2}(),. \delta()$. & 517.38 & 0.99 & 0.15 & 0.60 & 10 & 494.60 \\
\hline$p_{1}($ distoforest $), p_{2}$ (distoforest $), \delta()$. & 517.62 & 1.22 & 0.13 & 0.54 & 17 & 475.86 \\
\hline$p_{1}($ disstoforest $), p_{2}(n d v i+$ distoforest $), \delta()$. & 518.24 & 1.85 & 0.10 & 0.39 & 18 & 472.61 \\
\hline$p_{1}(n d v i), p_{2}($ distoforest $), \delta()$. & 518.36 & 1.97 & 0.09 & 0.37 & 17 & 475.86 \\
\hline$p_{1}(n d v i+$ distoforest $), p_{2}($ distoforest $), \delta()$. & 520.61 & 4.21 & 0.03 & 0.12 & 18 & 474.97 \\
\hline$p_{1}(n d v i+$ distoforest $), p_{2}(n d v i+$ distoforest $), \delta()$. & 521.31 & 4.92 & 0.02 & 0.08 & 19 & 472.45 \\
\hline$p_{1}(),. p_{2}(n d v i), \delta()$. & 521.34 & 4.94 & 0.02 & 0.08 & 16 & 481.89 \\
\hline$p_{1}(n d v i), p_{2}(n d v i), \delta()$. & 532.27 & 5.26 & 0.01 & 0.07 & 17 & 479.15 \\
\hline$p_{1}(),. p_{2}(),. \delta()$. & 532.27 & 15.88 & 0.00 & 0.00 & 15 & 495.79 \\
\hline$p_{1}(n d v i), p_{2}(),. \delta()$. & 532.32 & 15.92 & 0.00 & 0.00 & 16 & 492.86 \\
\hline$p_{1}($ distoforest $), p_{2}(n d v i), \delta()$. & 535.10 & 18.71 & 0.00 & 0.00 & 17 & 492.60 \\
\hline$p_{1}(n d v i+$ distforest $), p_{2}(),. \delta()$. & 535.20 & 18.80 & 0.00 & 0.00 & 17 & 492.70 \\
\hline$p_{1}(n d v i+$ distoforest $), p_{2}(n d v i), \delta()$. & 536.91 & 20.52 & 0.00 & 0.00 & 18 & 491.28 \\
\hline
\end{tabular}

${ }^{1}$ Covariates: distoforest, distance to nearest forest patch; dog, relative abundance of dogs; goat, relative abundance of goats; $n d v i$, normalized difference vegetation index; river, cumulative length of rivers in a grid cell.

${ }^{2}$ Akaike information criterion adjusted for small sample size.

${ }^{3}$ Difference in AICc to best performing model.

about factors influencing spatial variation on $\Psi_{1}$ and $\Psi_{2}$. We used a logit link function to assess model parameters as a function of covariates (Mackenzie et al., 2002). Nineteen alternate models were implemented to test our hypothesis.
We included covariates for $\Psi_{1}$ and $\Psi_{2}$ singly, or in additive combinations (see Table 3 for a complete list of models). Again we evaluated model support using AICc. Analysis was carried out in MARK 8.o (White, 2019).

TABLE 3 Model results for probabilities of leopard habitat use $\left(\Psi_{1}\right)$ and predation on domestic animals $\left(\Psi_{2}\right)$, based on a priori hypotheses. For all models, covariates $n d v i$ and distoforest were used to explain variation in detection probability.

\begin{tabular}{|c|c|c|c|c|c|c|}
\hline Model $^{1}$ & $\mathrm{AICc}^{2}$ & $\Delta \mathrm{AICc}^{3}$ & $\begin{array}{l}\text { Akaike } \\
\text { weight }\end{array}$ & $\begin{array}{l}\text { Model } \\
\text { likelihood }\end{array}$ & $\begin{array}{l}\text { No. of } \\
\text { parameters }\end{array}$ & Deviance \\
\hline$\Psi_{1}($ dog $+n d v i), \Psi_{2}$ (goat + river $)$ & 513.68 & 0.00 & 0.19 & 1.00 & 13 & 482.89 \\
\hline$\Psi_{1}(\operatorname{dog}+n d v i), \Psi_{2}($ goat + dog $)$ & 513.96 & 0.27 & 0.17 & 0.87 & 13 & 483.17 \\
\hline$\Psi_{1}(d o g+n d v i), \Psi_{2}($ goat $+n d v i)$ & 514.29 & 0.60 & 0.14 & 0.74 & 13 & 483.50 \\
\hline$\Psi_{1}($ dog + goat $+n d v i), \Psi_{2}($ goat $+n d v i)$ & 514.87 & 1.18 & 0.10 & 0.55 & 14 & 481.27 \\
\hline$\Psi_{1}($ dog $+n d v i), \Psi_{2}($ dog + goat $+n d v i)$ & 515.50 & 1.81 & 0.08 & 0.40 & 14 & 481.90 \\
\hline$\Psi_{1}($ dog $+n d v i), \Psi_{2}($ dog + goat + river $)$ & 515.62 & 1.93 & 0.07 & 0.37 & 14 & 482.02 \\
\hline$\Psi_{1}($ distoforest + river $+n d v i), \Psi_{2}($ goat $+n d v i)$ & 516.06 & 2.37 & 0.06 & 0.30 & 14 & 482.46 \\
\hline$\Psi_{1}(d o g+\operatorname{dog} \times \operatorname{dog}+n d v i), \Psi_{2}($ goat $+n d v i)$ & 516.81 & 3.12 & 0.04 & 0.20 & 14 & 483.21 \\
\hline$\Psi_{1}($ dog + goat $+n d v i), \Psi_{2}($ dog + goat $+n d v i)$ & 517.20 & 3.51 & 0.03 & 0.17 & 15 & 480.72 \\
\hline$\Psi_{1}($ distoforest + river $+n d v i), \Psi_{2}($ goat + river $+n d v i)$ & 517.58 & 3.89 & 0.02 & 0.14 & 15 & 481.09 \\
\hline$\Psi_{1}($ dog + goat $), \Psi_{2}($ dog + goat $)$ & 517.67 & 3.98 & 0.02 & 0.13 & 13 & 486.88 \\
\hline$\Psi_{1}($ distoforest + river $+n d v i+$ dog $), \Psi_{2}$ (goat + river $)$ & 519.83 & 6.14 & 0.00 & 0.04 & 15 & 483.34 \\
\hline $\begin{array}{l}\Psi_{1}(\text { distoforest }+ \text { river }+n d v i+\text { dog }+ \text { goat }) \\
\Psi_{2}(\text { distoforest }+ \text { river }+n d v i+\text { dog }+ \text { goat })\end{array}$ & 521.31 & 7.62 & 0.00 & 0.02 & 19 & 472.45 \\
\hline Intercept only & 521.56 & 7.87 & 0.00 & 0.01 & 9 & 501.31 \\
\hline$\Psi_{1}($ distoforest + river $+n d v i+$ dog $), \Psi_{2}($ dog + goat $+n d v i)$ & 521.59 & 7.90 & 0.00 & 0.01 & 15 & 485.10 \\
\hline$\Psi_{1}($ distoforest $+n d v i), \Psi_{2}($ distoforest $+n d v i)$ & 523.57 & 9.88 & 0.00 & 0.00 & 13 & 492.78 \\
\hline$\Psi_{1}($ river $+n d v i), \Psi_{2}($ river $+n d v i)$ & 523.83 & 10.14 & 0.00 & 0.00 & 13 & 493.04 \\
\hline$\Psi_{1}($ distoforest + river $), \Psi_{2}$ (distoforest $\left.+n d v i\right)$ & 524.41 & 10.72 & 0.00 & 0.00 & 13 & 493.62 \\
\hline$\Psi_{1}($ distoforest + river $+n d v i), \Psi_{2}($ distoforest + river $+n d v i)$ & 525.38 & 11.69 & 0.00 & 0.00 & 15 & 488.89 \\
\hline
\end{tabular}

${ }^{1}$ Covariates: distoforest, distance to nearest forest patch; dog, relative abundance of dogs; goat, relative abundance of goats; ndvi, normalized difference vegetation index; river, cumulative length of rivers in a grid cell.

${ }^{2}$ Akaike information criterion adjusted for small sample size.

${ }^{3}$ Difference in AICc to best performing model. 


\section{Results}

We conducted interviews in 321 households in 90 grid cells, covering 10 municipalities within Kathmandu district. Sixty per cent of the respondents were farmers primarily dependent on agriculture, and others were engaged in livelihoods such as business and service in government institutions or private enterprises. Mean land holding size of respondents 0.12 ha (range $0-2.1 \mathrm{ha}$ ), and $69 \%$ of respondents identified themselves as middle class, with a monthly income of USD 100-300. Interviewees were aged $18-80$ years, with a mean age of 39 years. Seventy-eight per cent of interviewees were men and $22 \%$ women.

The naïve probability of leopard habitat use was $63 \%$ and predation on domestic animals was recorded in $34 \%$ of the surveyed cells. Respondents reported leopard predation on goats (14\% of respondents) and dogs (18\%), but no human deaths or injuries. The reported losses resulting from depredation of goats were valued at a total of USD 5,790.

Amongst 15 candidate models to assess the influence of covariates on detection probabilities associated with $p_{1}$ (leopard detection probability when true state is 1 ) and $p_{2}$ (detection probability when true state is 2), eight models (with combination of covariates distance to forest and NDVI) accumulated $>95 \%$ Akaike weight (Table 2). Because both distance to forest and NDVI covariates appeared in the eight best supported models, the model carried forward into the next step of analysis included these covariates (additively) to address heterogeneity in $p_{1}$ and $p_{2}$. No single model was particularly well supported (Table 2 ). The model averaged estimate of $p_{1}$ was $0.28 \pm \mathrm{SE} 0.09$ and $p_{2}$ was $0.51 \pm$ SE 0.06 . The model averaged estimate for $\delta$ (probability of finding evidence of leopard predation on domestic animals) was $0.46 \pm$ SE 0.05 .

Of 19 candidate models run to estimate leopard habitat use with and without predation on domestic animals $\left(\Psi_{1}\right.$ and $\Psi_{2}$ ), no single model was particularly well supported. The best model, $\Psi_{1}(\operatorname{dog}+n d v i), \Psi_{2}$ (goat + river $)$, had $19 \%$ of the overall model weight. The additive covariates relative abundance of dogs and NDVI were associated with $\Psi_{1}$ in the six best supported models (which cumulatively accounted for $>75 \%$ of the overall support). For the parameter $\Psi_{2}$, the relative abundance of goats was associated with these top six models, in combination with one or more of the other covariates (dog abundance, river length and NDVI; Table 3). The model averaged estimate (across all 19 models) of $\Psi_{1}$ was $0.96+$ SE 0.05 , indicating nearubiquitous leopard presence across the study area. The corresponding estimate for $\Psi_{2}$ was $0.76+$ SE 0.15 , indicating that depredation on domestic animals occurs in many cells with leopard use.

Given extensive leopard occurrence, none of the covariates in our models had statistically significant influence on the parameter $\Psi_{1}$ (MacKenzie et al., 2002; Table 4). The parameter $\Psi_{2}$ was positively associated with goat abundance $\hat{\beta}=2.28 \pm$ SE 0.92. Probability of habitat use with predation increased when the goat encounter rate was $>4$, and fell away steeply at lower values of this covariate (Fig. 2). Relative abundance of dogs and normalized difference vegetation index were positively associated with probability of livestock depredation in cells with leopard site use $\hat{\beta}=0.70 \pm$ SE 0.57; $\hat{\beta}=0.54 \pm$ SE 0.49 , although there was considerable uncertainty in these estimates. River length and distance to forest did not have any discernible effect on the parameters $\Psi_{1}$ and $\Psi_{2}$ based on these data.

\section{Discussion}

Our finding that leopards occur extensively in areas with high human densities in Kathmandu district is of significance for a number of reasons. Firstly, it establishes that this leopard population is well adapted to exploiting farmlands and human settlements in a densely populated landscape, with near-ubiquitous occurrence over the study area. Our findings corroborate those of Athreya et al. (2013) from Maharashtra state in India, where leopards move extensively within an agricultural landscape. We note, however, that the Kathmandu valley is more densely populated than areas such as rural Maharashtra. Secondly, we ascertained that c. $76 \%$ of the area around Kathmandu city is subject to varying levels of leopard predation on domestic animals (Fig. 3). Remarkably, despite the widespread distribution of leopards, attacks on people are infrequent. Our findings, however, do suggest that leopards may use both adjacent forests and peri-urban habitats, where they prey upon domestic animals and gain access to additional food resources. This leads us to conjecture that leopards have a predilection to spend longer periods in these peri-urban areas.

We found that the relationship between leopard habitat use and relative abundance of dogs is variable. Although dogs attract leopards (Athreya et al., 2014), they may also repel leopards. Dogs in Kathmandu occur in a density of 5 animals/ha (Kakati, 2010) and our observations indicate that they generally form packs and live in clusters. An explanation for the possible ambiguity in the relationship between leopard habitat use and relative abundance of dogs could be that dog packs may detect and repel leopards away from human settlements. In addition, reporting of predation on stray dogs may be incomplete. More research is required to obtain robust, spatially explicit estimates of dog and leopard populations in the study area, and examine the interactions of these species in peri-urban areas.

Our research raises an important question: if leopards are widely distributed and frequently predate on dogs and goats, why are encounters between people and leopards rare in the Kathmandu valley? This is in contrast to some other areas of the Himalayas (Naha et al., 2018), where people have 
TABLE 4 Estimates of $\beta$-coefficient values (with standard errors) for individual covariates associated with probabilities of leopard presence $\left(\Psi_{1}\right)$ and predation on domestic animals $\left(\Psi_{2}\right)$ for 19 models. For all models, covariates $n d v i$ and distoforest were fixed with detection probabilities $p_{1}$ and $p_{2}$.

\begin{tabular}{|c|c|c|c|c|c|c|c|c|c|c|c|}
\hline Model $^{1}$ & $\Psi_{1}(.) \pm \mathrm{SE}$ & $\begin{array}{l}\Psi_{1} \\
\operatorname{dog} \pm \mathrm{SE}\end{array}$ & $\begin{array}{l}\Psi_{1} \\
\text { goat } \pm \text { SE }\end{array}$ & $\begin{array}{l}\Psi_{1} \\
n d v i \pm \mathrm{SE}\end{array}$ & $\begin{array}{l}\Psi_{1} \\
\text { river } \pm \mathrm{SE}\end{array}$ & $\begin{array}{l}\Psi_{1} \\
\text { distoforest } \\
\pm \text { SE }\end{array}$ & $\Psi_{2}(.) \pm \mathrm{SE}$ & $\Psi_{2} \operatorname{dog} \pm \mathrm{SE}$ & $\Psi_{2}$ goat \pm SE & $\Psi_{2} n d v i \pm \mathrm{SE}$ & $\Psi_{2}$ river $\pm \mathrm{SE}$ \\
\hline $\begin{array}{l}\Psi_{1}(\text { dog }+n d v i) \\
\Psi_{2}(\text { goat }+ \text { river })\end{array}$ & $3.45 \pm 1.65$ & $-1.02 \pm 0.69$ & & $2.31 \pm 1.34$ & & & $0.78 \pm 0.56$ & & $2.28 \pm 0.92$ & & $-0.67 \pm 0.48$ \\
\hline $\begin{array}{l}\Psi_{1}(\text { dog }+n d v i), \\
\Psi_{2}(\text { goat }+n d v i)\end{array}$ & $3.75 \pm 2.05$ & $-1.09 \pm 0.79$ & & $2.36 \pm 1.51$ & & & $0.84 \pm 0.59$ & & $2.29 \pm 0.97$ & $0.54 \pm 0.49$ & \\
\hline $\begin{array}{c}\Psi_{1}(\text { dog }+ \text { goat }+n d v i) \\
\Psi_{2}(\text { goat }+n d v i)\end{array}$ & $4.05 \pm 2.03$ & $1.51 \pm 1.21$ & $0.90 \pm 0.90$ & $-1.33 \pm 0.99$ & & & $2.38 \pm 1.41$ & & $4.47 \pm 2.06$ & $1.99 \pm 0.91$ & \\
\hline $\begin{array}{l}\Psi_{1}(\text { dog }+ \text { ndvi }) \\
\quad \Psi_{2}(\text { dog }+ \text { goat }+ \text { river })\end{array}$ & $3.31 \pm 1.45$ & $-1.01 \pm 0.65$ & & $2.27 \pm 1.20$ & & & $0.83 \pm 0.56$ & $0.49 \pm 0.53$ & $2.24 \pm 0.89$ & & $-0.54 \pm 0.51$ \\
\hline $\begin{array}{l}\Psi_{1}(\text { distoforest }+ \text { river }+n d v i) \\
\Psi_{2}(\text { goat }+n d v i)\end{array}$ & $3.41 \pm 1.98$ & & & $0.53 \pm 0.65$ & $-0.04 \pm 0.72$ & $2.67 \pm 2.69$ & $4.13 \pm 3.36$ & & $6.75 \pm 4.76$ & $2.47 \pm 1.45$ & \\
\hline $\begin{array}{l}\Psi_{1}(\text { dog }+\operatorname{dog} \times \operatorname{dog}+n d v i) \\
\Psi_{2}(\text { goat }+n d v i)\end{array}$ & $3.43 \pm 1.75$ & $-1.36 \pm 1.05$ & & $2.29 \pm 1.30$ & & & $0.86 \pm 0.59$ & & $2.26 \pm 0.98$ & $0.52 \pm 0.49$ & \\
\hline
\end{tabular}

${ }^{1}$ Covariates: distoforest, distance to nearest forest patch; dog, relative abundance of dogs; goat, relative abundance of goats; $n d v i$, normalized difference vegetation index; river, cumulative length of rivers in a grid cell. 


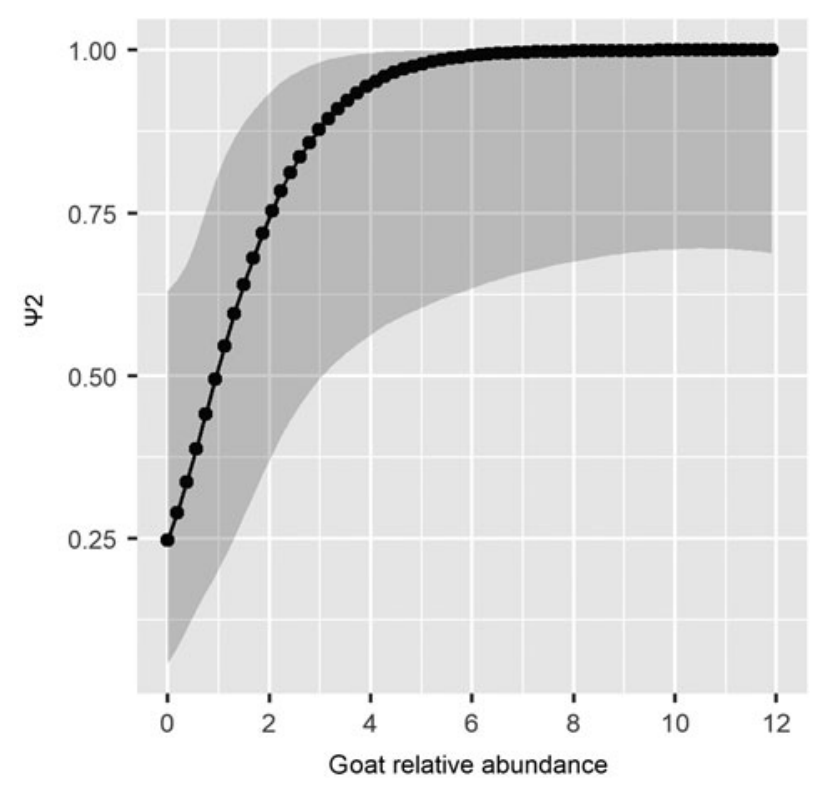

FIG. 2 Relationship between occurrence of predation $\left(\Psi_{2}\right)$ and relative abundance of goats. The black dots and line show the mean value and the grey area represents the $95 \% \mathrm{CI}$.

frequently been injured or killed by leopards. We posit that most settlements within our study area have amenities such as street lights and toilets within homes, which reduce close interaction between humans and leopards, even in shared spaces. Odden et al. (2014) reported that leopards adapt their behaviour to avoid humans, and predominantly use areas within settlements at night.

Leopard habitat use and predation on domestic animals in Kathmandu district also needs to be understood in the context of the ecology of predators and prey in the forests around the city. Forests in the mid-hills of Nepal generally support sparse populations of wild prey (Acharya et al., 2016), which may push leopards into human-dominated habitats where they can predate upon domestic animals with relative ease (Kabir et al., 2013). There is no information on the distribution and abundance of wild prey species of leopards in the Shivapuri-Nagarjun National Park and Kathmandu Forest Division. Carrying out a baseline assessment of prey and predator populations in this forest is thus a priority area for future research, to examine the proximate drivers of predation on domestic animals in the Kathmandu valley. Moreover, expansion of human settlements into wilderness areas increases spatial overlap between people and carnivores, and the risk of negative interactions (Woodroffe, 2000). Our research calls for urban planners to consider these factors when delineating plans for urban development in the Kathmandu valley, to limit encroachment of human settlements into natural habitats.

A key limitation of our study is that it does not account for false positives in responses (leopard presence and predation on domestic animals may have been reported in (a) Probability of habitat use

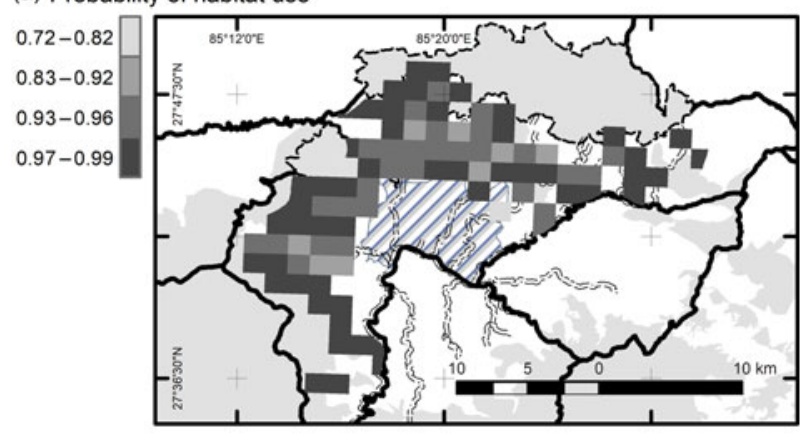

(b) Probability of predation on domestic animals

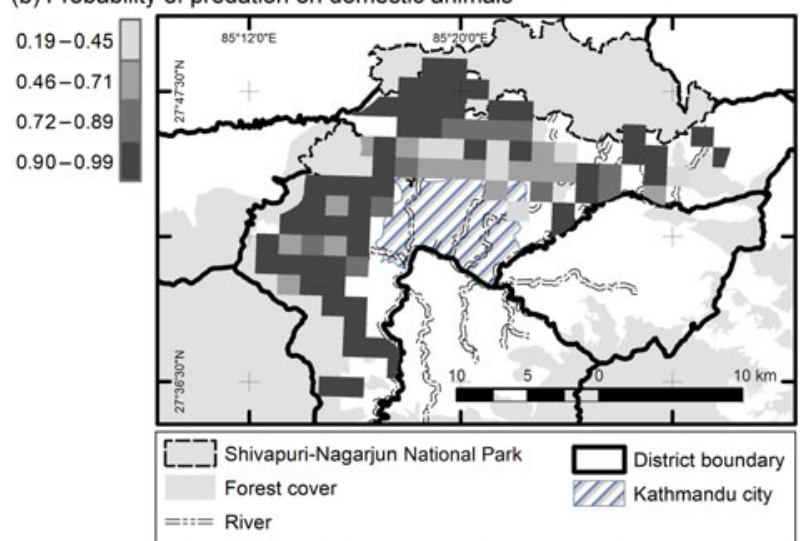

FIG. 3 (a) Probability of habitat use of leopard in peri-urban Kathmandu within $2 \mathrm{~km}^{2}$ survey grid cells, and (b) probability of occurrence of predation on domestic animals. These estimates are from the best-ranked model $\Psi_{1}(\operatorname{dog}+n d v i), \Psi_{2}$ (goat+river).

areas where the true state was o or 1). This is because we do not have independent data sources (e.g. from camera traps or sign surveys) or information to differentiate between more and less reliable observers. False positives in the data can introduce bias in the parameter estimates (Royle \& Link, 2006; Petracca et al., 2018). We note that our results are therefore preliminary, although it is common for occupancy surveys using interview data to not account for false positives, particularly when these are rapid surveys or studies carried out using modest budgets (Ghoshal et al., 2019; Srivathsa et al., 2019). Future studies should build on our initial work by combining sign surveys or camera trapping with interview data, to account for potential false positives. Robust estimates of dog abundance may be derived by rigorous sampling coupled with mark-resight models (Punjabi et al., 2012), in lieu of encounter rates.

\section{Management and policy recommendations}

Negative human-leopard interactions in Kathmandu district are an increasing problem. During our study period, leopards were captured and removed from three locations within urban areas. We anticipate that conflict may be 
exacerbated by increasing human and livestock populations and progressive urbanization that may create ecological traps as the landscape is further fragmented. Thus comprehensive strategies are needed to mitigate conflict. We propose a two-pronged approach. Firstly, a framework is required for the systematic monitoring of leopards in the area, for which our study can serve as a template. Secondly, a comprehensive conflict mitigation plan should be created, including education and awareness programmes, control of free-ranging dogs (with monitoring to assess any potential unintended adverse effects such as increased predation on livestock), measures to prevent attacks on livestock (e.g. predator-proof corrals), compensation programmes and rapid response teams to ensure human and animal welfare in conflict-prone areas. These teams must include personnel trained in animal capture and crowd control. Careful deliberation is needed on whether and where captured leopards should be translocated (Athreya et al., 2011). Effective conflict mitigation planning and implementation of plans will require the collaboration of various stakeholders including government departments, veterinarians, ecologists and community representatives. Ultimately, plans will need to recognize that a strict separation of people and leopards may not be feasible in the Kathmandu valley, and they must therefore also include measures that enable coexistence in shared spaces.

Acknowledgements We thank the Department of National Parks and Wildlife Conservation of the Government of Nepal for permission to carry out this study. We acknowledge the financial support provided by National Trust for Nature Conservation under IDA project no. H6660. We acknowledge the contribution of Sujhav Pun and $\mathrm{Mr}$ Bishwanath for their support in coordination; and Nirmal Magar, Surendar Magar and Sagar Bhattarai for assistance in field data collection.

Author contributions Study design and fieldwork: $\mathrm{AB}$; data analysis: $\mathrm{AB}, \mathrm{PC}$; writing: $\mathrm{AB}$; revisions: all authors.

\section{Conflicts of interest None.}

Ethical standards This research abided by the Oryx guidelines on ethical standards. We obtained verbal consent from each respondent before starting the interview.

\section{References}

Acharya, K.P., Paudel, P.K., Neupane, P.R. \& Köhl, M. (2016) Human-wildlife conflicts in Nepal: patterns of human fatalities and injuries caused by large mammals. PLOS ONE, 11, eo161717.

Allendorf, T.D. (2010) A framework for the park-people relationship: insights from protected areas in Nepal and Myanmar. International Journal of Sustainable Development \& World Ecology, $17,417-422$.

Athreya, V., Odden, M., Linnell. \& Karanth, K.U. (2011)

Translocation as a tool for mitigating conflict with leopards in human-dominated landscapes of India. Conservation Biology,

25, 133-141.

Athreya, V., Odden, M., Linnell, J.D., Krishnaswamy, J. \& KARANTH, K.U. (2013) Big cats in our backyards: persistence of large carnivores in a human dominated landscape in India. PLOS ONE, 8, e57872.

Athreya, V., Odden, M., Linnell, J.D., Krishnaswamy, J. \& Karanth, K.U. (2014) A cat among the dogs: leopard Panthera pardus diet in a human-dominated landscape in western Maharashtra, India. Oryx, 50, 156-162.

Athreya, V., Srivathisa, A., Puri, M., Karanth, K.K., Kumar, N.S. \& KarAnTH, K.U. (2015) Spotted in the news: using media reports to examine leopard distribution, depredation, and management practices outside protected areas in Southern India. PLOS ONE, 10, e0142647.

Barua, M., Bhagwat, S.A. \& Jadhav, S. (2013) The hidden dimensions of human-wildlife conflict: health impacts, opportunity and transaction costs. Biological Conservation, 157, 309-316.

Bateman, P.W. \& Fleming, P.A. (2012) Big city life: carnivores in urban environments. Journal of Zoology, 287, 1-23.

BeCKMAnN, J.P. \& LaCKey, C.W. (2008) Carnivores, urban landscapes, and longitudinal studies: a case history of black bears. Human-Wildlife Conflicts, 2, 168-174.

CBS (Central Bureau of S Tatistics) (2014) National Population and Housing Census 2011. Central Bureau of Statistics, Kathmandu, Nepal. cbs.gov.np [accessed 28 October 2020].

Dar, N.I., Minhas, R.A., Zaman, Q. \& Linkie, M. (2009) Predicting the patterns, perceptions and causes of human-carnivore conflict in and around Machiara National Park, Pakistan. Biological Conservation, 142, 2076-2082.

Dickman, A.J. \& Marker, L.L. (2005) Factors affecting leopard (Panthera pardus) spatial ecology, with particular reference to Namibian farmlands. South African Journal of Wildlife Research, $35,105-115$.

Edgaonkar, A. \& Chellam, R. (2002) Food habit of the leopard, Panthera pardus, in the Sanjay Gandhi National Park, Maharashtra, India. Mammalia, 66, 353-360.

Enserink, E. \& Vogel, G. (2006) The carnivore comeback. Science, $314,746-749$.

GeHRT, S.D. (2007) Ecology of Coyotes in Urban Landscapes. Wildlife Damage Management Conferences, Proceedings, 63. University of Nebraska, Lincoln, USA.

Ghoshal, A., Bhatnagar, Y.V., Pandav, B., Sharma, K., Mishra, C., Raghunath, R. \& Suryawanshi, K.R. (2019) Assessing changes in distribution of the Endangered snow leopard Panthera unica and its wild prey over 2 decades in the Indian Himalaya through interview-based occupancy surveys. Oryx, 53, 620-632.

Hayward, M.W., Henschel, P., O'Brien, J., Hofmeyr, M., Balme, G. \& Kerley, G.I.H. (2006) Prey preferences of the leopard (Panthera pardus). Journal of Zoology, 270, 298-313.

Ishtiaque, A., Shrestha, M. \& Chhetri, N. (2017) Rapid urban growth in the Kathmandu valley, Nepal: monitoring land use land cover dynamics of a Himalayan city with landsat imageries. Environments, 4, 72.

Kabir, M., Ghoddousi, A., Awan, M.S. \& Awan, M.N. (2013) Assessment of human-leopard conflict in Machiara National Park, Azad Jammu and Kashmir, Pakistan. European Journal of Wildlife Research, 60, 291-296.

Ka Kati, K. (2010) Street Dog Population Survey, Kathmandu 2010. Final report to the World Society for the Protection of Animals, London, UK. katcentre.org.np [accessed 2 July 2019].

Karanth, K.U. \& Sunquist, M.E. (1995) Prey selection by tiger, leopard and dhole in tropical forests. Journal of Animal Ecology, 64, 439-450. 
Karanth, K.U. \& Sunquist, M.E. (2000) Behavioural correlates of predation by tiger (Panthera tigris), leopard (Panthera pardus) and dhole (Cuon alpinus) in Nagarhole, India. Journal of Zoology, 250, 255-265.

Khorozyan, I., Soffi, M., Soufi, M., Hamidi, A.K., Ghoddousi, A. \& Waltert, M. (2017) Effects of shepherds and dogs on livestock depredation by leopards (Panthera pardus) in north-eastern Iran. Peer J, 5, e3049.

KIsSUI, B.M. (2008) Livestock predation by lions, leopards, spotted hyenas, and their vulnerability to retaliatory killings in the Maasai steppe, Tanxania. Animal Conservation, 11, 422-432.

Krishna, Y.C., Krishnaswamy, J. \& Kumar, N.S. (2008) Habitat factors affecting site occupancy and relative abundance of four-horned antelope. Journal of Zoology, 276, 63-70.

Kshettry, A., Vaidyanathan, S. \& Athreya, V. (2017) Leopard in a tea-cup: a study of leopard habitat-use and human-leopard interactions in north-eastern India. PLOS ONE, 12, e0177013.

Kshettry, A., Vaidyanathan, S. \& Athreya, V. (2018) Diet selection of leopards (Panthera pardus) in a human-use landscape in north-eastern India. Tropical Conservation Science, 11, 1940082918764635 .

Kumbhojkar, S., Yosef, R., Kosicki, J.Z., Kwiatkowska, P.K. \& Tryjanowski, P. (2020) Dependence of the leopard Panthera pardus fusca in Jaipur, India, on domestic animals. Oryx, published online 2 October 2020

MacKenzie, D.I., Nichols, J.D., Lachman, G.B., Droege, S., Andrew Royle, J. \& Langtimm, C.A. (2002) Estimating site occupancy rates when detection probabilities are less than one. Ecology, 83, 2248-2255.

MacKenzie, D.I., Nichols, J.D., Royle, J.A., Pollock, K.H., Bailey, L. \& Hines, J.E. (2006) Occupancy Estimation and Modeling: Inferring Patterns and Dynamics of Species Occurrence. Elsevier, Amsterdam, The Netherlands.

Megaze, A., Balakrishnan, M. \& Belay, G. (2017) Human-wildlife conflict and attitude of local people towards conservation of wildlife in Chebera Churchura National Park, Ethiopia. African Zoology, 52, 1-8.

Naha, D., Sathyakumar, S. \& Rawat, G.S. (2018) Understanding drivers of human-leopard conflicts in the Indian Himalayan region: spatio-temporal patterns of conflicts and perception of local communities towards conserving large carnivores. PLOS ONE, 13, e0204528.

Nichols, J.D., Hines, J.E., Mackenzie, D.I., Seamans, M.E. \& Gutierrez, R.J. (2007) Occupancy estimation and modeling with multiple states and state uncertainty. Ecology, 88, 1395-1400.

Nyhus, P.J. \& Tilson, R. (2004) Characterizing human-tiger conflict in Sumatra, Indonesia: implications for conservation. Oryx, 38, 68-74

OdDEN, M. \& WegGe, P. (2005) Spacing and activity patterns of leopards Panthera pardus in the Royal Bardia National Park, Nepal. Wildlife Biology, 11, 145-152.

Odden, M., Wegge, P. \& Fredriksen, T. (2010) Do tigers displace leopards? If so, why? Ecological Research, 25, 875-881.

Odden, M., Athreya, V., Rattan, S. \& Linnell, J.D. (2014) Adaptable neighbours: movement patterns of GPS-collared leopards in human dominated landscapes in India. PLOS ONE, 9, e112044

Ogada, M.O., Woodroffe, R., OGuge, N.O. \& Frank, L.G. (2003) Limiting depredation by African carnivores: the role of livestock husbandry. Conservation Biology, 17, 1521-1530.

Petracca, L.S., Frair, J.L., Cohen, J.B., Calderon, A.P., Carazo-Salazar, J., Castaneda, F. et al. (2018) Robust inference on large-scale species habitat use with interview data: the status of jaguars outside protected areas in Central America. Journal of Applied Ecology, 55, 723-734.

Pokharel, M. (2015) Human-leopard conflict in the Kathmandu valley, Nepal. MSc thesis, Tribhuvan University, Kirtipur, Nepal.

Potgieter, G.C., Kerley, G.I. \& Marker, L.L. (2015) More bark than bite? The role of livestock guarding dogs in predator control on Namibian farmlands. Oryx, 50, 514-522.

Punjabi, G.A., Athreya, V. \& Linnell, J.D. (2012) Using natural marks to estimate free-ranging dog Canis familiaris abundance in a MARK-RESIGHT framework in suburban Mumbai, India. Tropical Conservation Science, 5, 510-520.

Ripple, W.J., Estes, J.A., Beschta, R.L., Wilmers, C.C., Ritchie, E. G., Hebblewhite, M. et al. (2014) Status and ecological effects of the world's largest carnivores. Science, 343, 1241484.

Ripple, W.J., Wofl, C., Newsome, T.M., Galetti, M., Alamgir, M., CRIST, E. et al. (2017) World scientists' warning to humanity: a second notice. BioScience, 67, 1026-1028.

RoYLE, J.A. \& LinK, W.A. (2006) Generalized site occupancy models allowing for false positive and false negative errors. Ecology, $87,835-841$.

SAngay, T. \& Vernes, K. (2008) Human-wildlife conflict in the Kingdom of Bhutan: patterns of livestock predation by large mammalian carnivores. Biological Conservation, 141, 1272-1282.

Seidensticker, J. (1976) On the ecological separation between tigers and leopards. Biotropica, 8, 225-234.

Shrestha, T.B. (2001) Forest diversity of Nepal's protected areas in the Mountains. Himalayan Review, 32, 25-29.

Smith, J.L.D. (1993) The role of dispersal in structuring the Chitwan tiger population. Behaviour, 124, 165-195.

Soulsbury, C.D. \& White, P.C. (2016) Human-wildlife interactions in urban areas: a review of conflicts, benefits and opportunities. Wildlife Research, 42, 541-553.

Srivathsa, A., Puri, M., Karanth, K.K., Patel, I. \& Kumar, S.K. (2019) Examining human-carnivore interactions using a socioecological framework: sympatric wild canids in India as a case study. Royal Society Open Science, 6, 182008.

SSNP (2017) Shivapuri Nagarjun National Park and Buffer Zone Management Plan. Shivapuri Nagarjun National Park, Kathmandu, Nepal.

Wang, S.W., Gebru, B.M., Lamchin, M., Kayastha, R.B. \& Lee, W. (2020) Land use and land cover change detection and prediction in the Kathmandu District of Nepal using remote sensing and GIS. Sustainability, 12, 3925.

White, G.C. (2019) Mark and Recapture Parameter Estimation Version 8.o. phidot.org/software/mark/downloads/index.html [accessed 28 October 2020].

Woodroffe, R. (200o) Predators and people: using human densities to interpret declines of large carnivores. Animal Conservation Forum, 3, 165-173.

Young, J.K., Olson, K.A., Reading, R.P., Amgalanbatar, S. \& BERGER, J. (2011) Is wildlife going to the dogs? Impacts of feral and free-roaming dogs on wildlife populations. BioScience, $61,125-132$.

Zeller, K.A., Nijhawan, S., Salom-Perez, R., Potosme, S. \& Hines, J.E. (2011) Integrating occupancy modeling and interview data for corridor identification: a case study for jaguars in Nicaragua. Biological Conservation, 144, 892-901.

Zérah, M.H. (2007) Conflict between green space preservation and housing needs: the case of the Sanjay Gandhi National Park in Mumbai. Cities, 24, 122-132. 